\title{
Torque Control During Intrusion on Upper Central Incisor in Labial and Lingual bracket System - A 3D Finite Element Study
}

\author{
Tejas R. Pol ${ }^{1}$, Meghna Vandekar ${ }^{2}$, Anuradha Patil ${ }^{3}$, Sanjana Desai ${ }^{4}$, Vikram Shetty ${ }^{5}$, Saptarshi Hazarika ${ }^{6}$
}

${ }^{1}$ Assistant professor Department of orthodontics, YMT Dental College and Hospital, kharghar, India

${ }^{2}$ HOD \& Professor, Department of orthodontics, YMT Dental College and Hospital, kharghar

${ }^{3}$ Associate Professor Department of conservative and Endodontics, Mgm dental college and hospital. New mumbai, India

${ }^{4}$ Associate Professor, Karnavati dental college, Ahemdabad, Gujrat, India

${ }^{5}$ Professor Department of orthodontics, YMT Dental College and Hospital, kharghar, India

${ }^{6}$ Lecturer Department of orthodontics, YMT Dental College and Hospital, kharghar, India

\section{Correspondence:}

b/1101, bhoomi paradise, sec 11

sanpada, navimumbai, India

400705

tejaspol21@gmail.com

Received: $24 / 10 / 2017$

Accepted: $18 / 11 / 2017$

Pol TR, Vandekar M, Patil A, Desai S, Vikram Shetty 5, Saptarshi Hazarika. Torque Control During Intrusion on Upper Central Incisor in Labial and Lingual bracket System - A 3D Finite Element Study. J Clin Exp Dent. 2018;10(1):e20-4. http://www.medicinaoral.com/odo/volumenes/v10i1/jcedv10ilp20.pdf

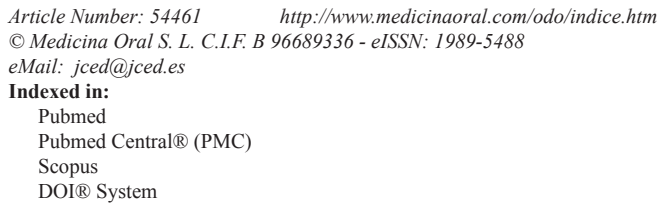

\begin{abstract}
Background: The aim of present study was to investigate the difference of torque control during intrusive force on upper central incisors with normal, under and high torque in lingual and labial orthodontic systems through 3D finite element analysis.

Material and Methods: Six 3D models of an upper right central incisor with different torque were designed in Solid Works 2006. Software ANSYS Version 16.0 was used to evaluate intrusive force on upper central incisor model . An intrusive force of $0.15 \mathrm{~N}$ was applied to the bracket slot in different torque models and the displacements along a path of nodes in the upper central incisor was assessed.

Results: On application of Intrusive force on under torqued upper central incisor in Labial system produce labial crown movement but in Lingual system caused lingual movement in the apical and incisal parts. The same intrusive force in normal-torqued central incisor led to a palatal movement in apical and labial displacement of incisal edge in Lingual system and a palatal displacement in apical area and a labial movement in the incisal edge in Labial systemin.

In overtorqued upper central incisor, the labial crown displacement in Labial system is more than Lingual system. Conclusions: In labial and lingual system on application of the same forces in upper central incisor with different inclinations showed different responses. The magnitudes of torque Loss during intrusive loads in incisors with normal, under and over-torque were higher in Labial system than Lingual orthodontic appliances.
\end{abstract}

Key words: FEM, lingual orthodontics, intrusion, torque control, labial bracket systems 


\section{Introduction}

Lingual Orthodontics (LiO), one of the most popular and rapidly growing esthetic orthodontic technique in the world and today is as popular as the labial technique among orthodontists and patients all over the world.

However, there are many clinical and biomechanical differences between the two techniques (1-4). It is essential for better orthodontic results to completely understand the biomechanical differences of torque control of the maxillary incisors during retraction between $\mathrm{LiO}$ and $\mathrm{LaO}$.

Hence, simply following the labial mechanics blindly and applying it in $\mathrm{LiO}$ can be inappropriate and may result in a less than optimal treatment results.

Nevertheless, lingual appliances have their own peculiar biomechanics, distinct from that of conventional orthodontics, and special care must be taken in their application.

From biomechanical point of view, one difference of labial and lingual systems would be the ability in torque control. According to Demling et al. in a comparative analysis of slot dimension claimed that slot precision in $\mathrm{LiO}$ is an important factor for minimal play of wire which results in three-dimensional control (5). In contrast, Liang et al. demonstrated that loss of torque control during retraction of upper incisors is more probably happen in extraction cases in $\mathrm{LiO}$ treatment. During retracting incisors in $\mathrm{LiO}$, the control of incisor torque is so important that since when lingual crown tipping appears, it is much more difficult to correct than in Labial orthodontics $(\mathrm{LaO})(6)$.

Clinically it is very difficult to evaluate the stress induced at various locations within the root by different types of orthodontic tooth movement. Although a variety of traditional analytical and experimental methods for analyzing dental stresses, such as photoelasticity, interferometric holography, and strain gauges, have given information on the mechanism of orthodontic tooth movement, they have been unable to clarify the microenvironmental changes around the periodontal ligament (PDL) and within the bone (7).

However, the finite element method (FEM) described by Zienkiewicz has been used to investigate a wide range of dentistry topics including tooth structure, $(8,9)$ biomaterials and restorations (8-10) and dental implants and root canals $(8,9)$ and may elucidate the reaction of the teeth, periodontal ligament, alveolar bone, etc. to orthodontic loading. FEM is a mathematical method in which the shape of complex geometric objects and their physical properties are computer-constructed. In order to capitalize on this powerful computational tool, we set out to make 3D FEM models. The purpose of this study was to evaluate and assess the torque control in labial and lingual orthodontic systems using light orthodontic forces during intrusion of normal, under and high torque upper central incisors in lingual and labial orthodontic systems using finite element method.

\section{Material and Methods}

Six 3D models of an upper right central incisor and its supporting structure were designed in Solid Works 2006 The tooth was modeled according to Ash's dental anatomy (Nelson. 2009) When designing the 3D FEM model, smaller elements were assigned to the areas with the potential for high-stress gradients, such as teeth, PDL, and adjacent alveolar bone.

The models were same except 2 points Torque:-undertorqued, normal-torqued, high torqued upper central Incisors, (Figs. 1,2).

The models were transferred to the ANSYS Version 16.0. Boundary conditions restricted displacements of the base of the models in all direction to prevent their rigid body motion. Mechanical properties (Table 1) were

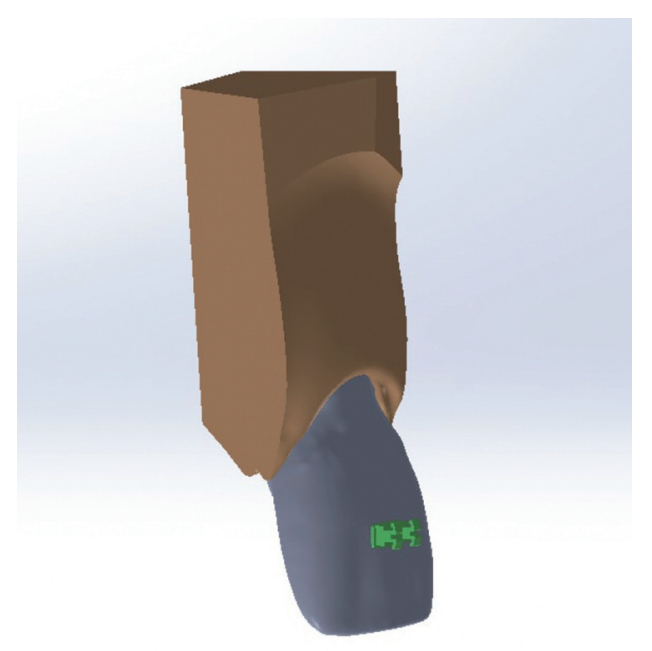

Fig. 1: 3D model of teeth with labial bracket.

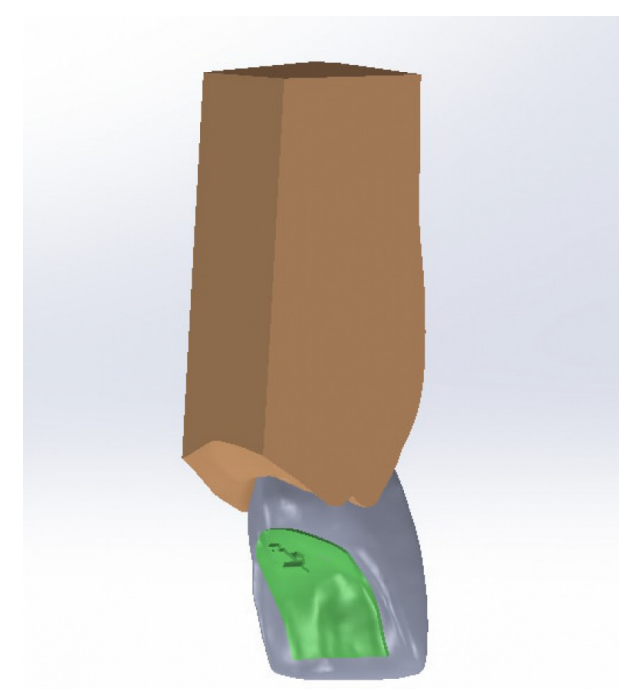

Fig. 2: 3D model of teeth with lingual bracket 
Table 1: Mechanical properties.

\begin{tabular}{|l|c|c|}
\hline & $\begin{array}{c}\text { Young's modulus } \\
(\mathbf{N} / \mathbf{m m})\end{array}$ & Poisson's Ratio \\
\hline Tooth & 20,000 & 0.30 \\
\hline PDL & 0.667 & 0.49 \\
\hline Cancellous Bone & 1370 & 0.30 \\
\hline Cortical Bone & 1,3700 & 0.26 \\
\hline
\end{tabular}

then applied and the models were meshed with 5119 nodes and 9367 elements (Fig. 3). (There was a slight difference between node and element numbers between models) A force of $0.15 \mathrm{~N}$ which is the appropriate magnitude of intrusion force 11 was applied to the bracket slot in different models and the displacements along a path of nodes in the upper central incisor was assessed.

\section{Results}

Negative findings represent a palatal displacement and positive ones show a labial movement.

Intrusive force of $0.15 \mathrm{~N}$ in under-torqued model in Lao induced labial crown movement $0.00144 \mathrm{~mm}$ ) and palatal root displacement $(-0.000583 \mathrm{~mm})$ but in Lio caused lingual movement in the apical $(-0.00009 \mathrm{~mm})$ and incisal parts $(0.000301 \mathrm{~mm})$ of the tooth (Fig. 4).

Application of the same force in normal-torqued central incisor led to a palatal movement in apical $(-0.000123$ $\mathrm{mm})$ and labial displacement in incisal edge $(0.0000326$ $\mathrm{mm}$ ) in LiO. In normal-torqued central incisor on application of intrusive force induced a palatal displacement in apical area $(-0.000456 \mathrm{~mm})$ and a labial movement in the incisal edge $(0.000614 \mathrm{~mm})$ in $\mathrm{LaO}$ (Fig. 5).

Over-torqued upper central incisor subjected to intrusive force showed labial crown displacement of the incisal edge in $\mathrm{LaO}(0.000621 \mathrm{~mm})$ and $\mathrm{LiO}(0.000323 \mathrm{~mm})$ (Fig. 6). In Over-torqued upper central incisor the crown displacement labially is more in lao than LiO. Palatal displacement of the apical area is noticed in both techniques, more in $\mathrm{LaO}(-0.000384 \mathrm{~mm})$ than $\mathrm{LiO}(-0.000292$ $\mathrm{mm})$.

\section{Discussion}

The present study was to investigate response of the upper incisor with normal, under and over torque to vertical load in labial and lingual orthodontic system through 3 Dimensional finite element study.

Intrusive forces act differently in both techniques because of the different location of force vectors in relation to the centre of resistance (12). Increasing the vertical intrusive force is one of the methods routinely used to prevent the uncontrolled tipping and obtain bodily type of movement in labial orthodontics ( $\mathrm{LaO})(13)$.

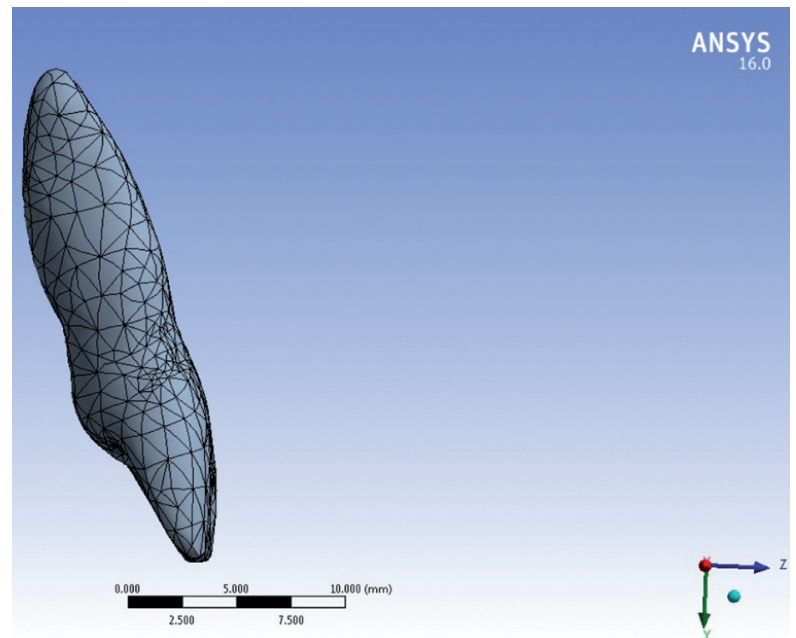

Fig. 3: 3D meshed model.

Geron et.al (14) stated that moments created in $\mathrm{LaO}$ are more than LiO, magnitude of crown displacement is more noticeable in LaO. According to Liang et al. (15) due to the shorter distance between the force application point and $\mathrm{C}$ res, the magnitude of lingual root torque during the intrusive loads is smaller in $\mathrm{LiO}$ than $\mathrm{LaO}$.

In this study, in normal, under and high torqued upper central incisors, in both systems a labial crown tipping was observed, labial crown displacement in $\mathrm{LaO}$ is more than LiO. The magnitudes of torque loss in intrusive movements in normal, under and high torqued upper central incisors were higher in $\mathrm{LaO}$ than $\mathrm{LiO}$.

Results of this study is in accordance with the findings of Jost-Brinkmann et al. (16) who claimed that during the vertical loading of upper incisors in LiO, a uniform stress distribution is seen which leads to more predictable tooth movements

According to Jost-Brinkmann et al. (16) application of force to a determined transitional point at which pure intrusion moments generated may induce the same results The findings are also in agreement with previous statement of Shum et al. (17) who showed that due to the closer distance of Cres and point of application in $\mathrm{LiO}$ during intrusion of a normal or over-torqued upper incisor, lesser moment and labial tipping is expected. 


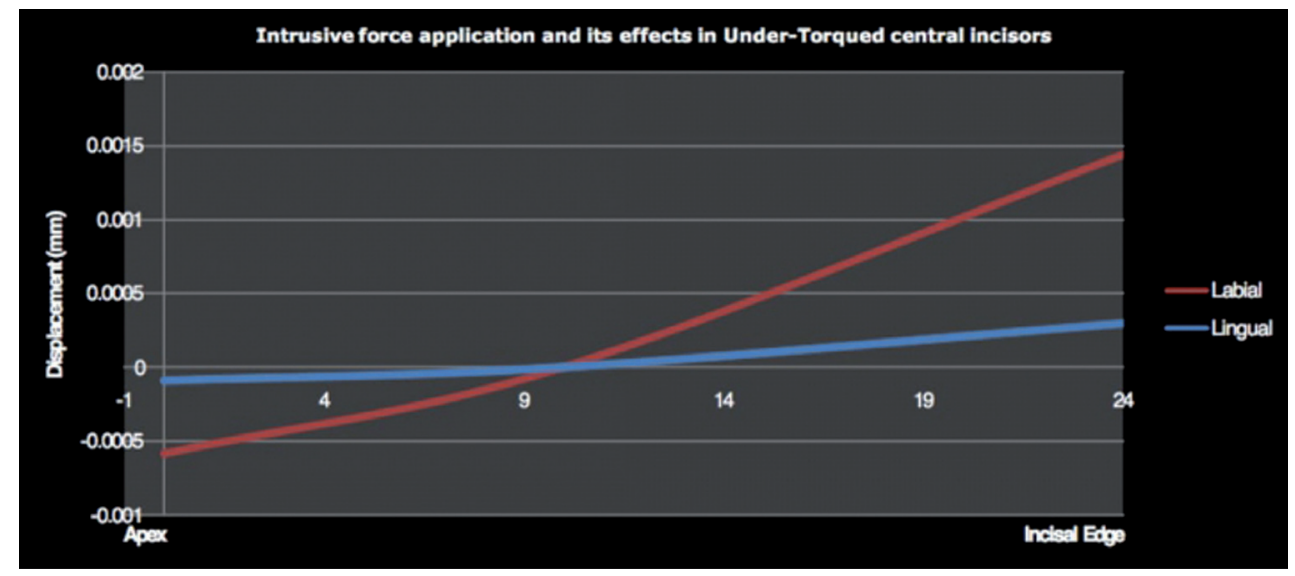

Fig. 4: Tooth displacement in under-torqued upper central incisor

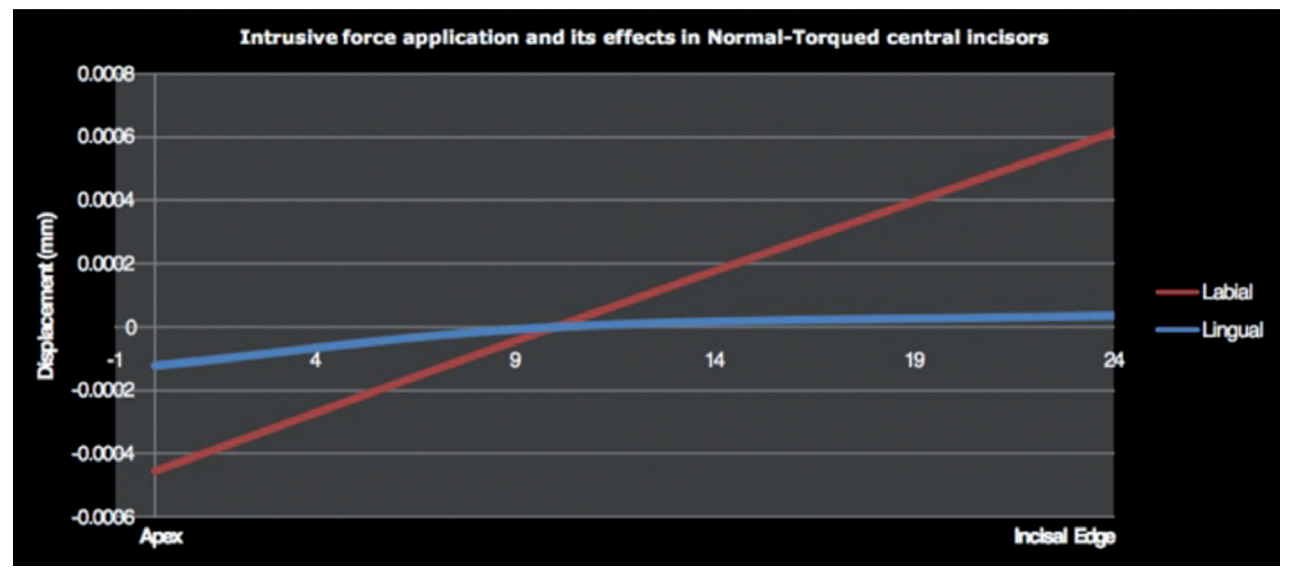

Fig. 5: Tooth displacement in normal-torqued upper central incisor.

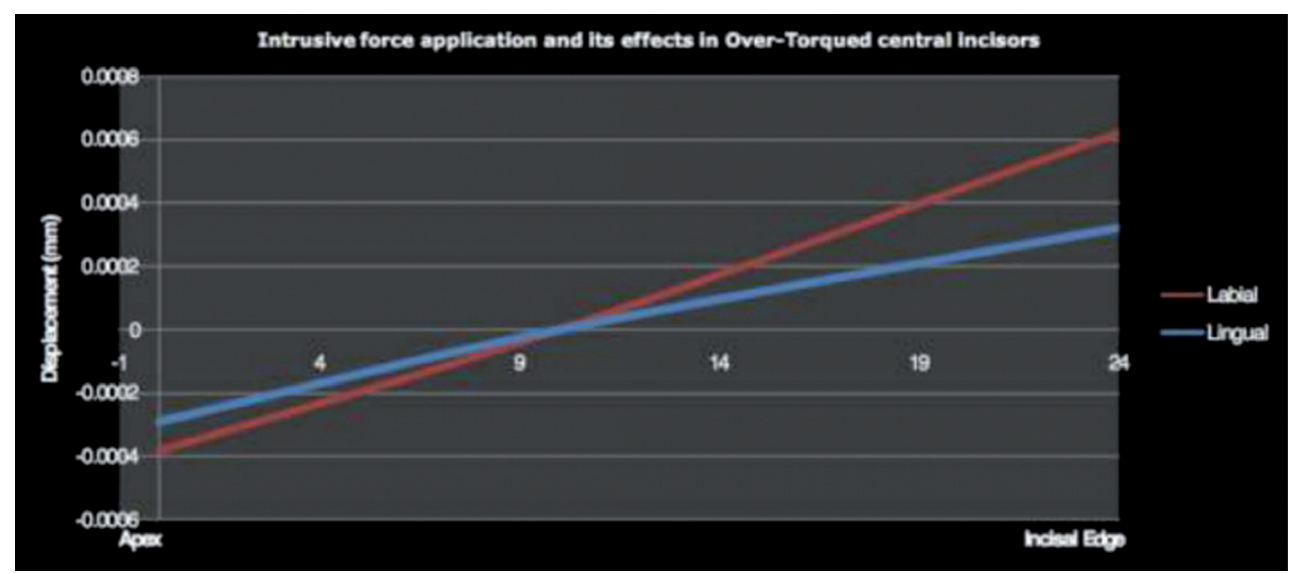

Fig. 6: Tooth displacement in over-torqued upper central incisor.

\section{Conclusions}

In $\mathrm{LiO}$, it is critical to control the moment/force ratio, retracting the incisors under mild forces and increasing lingual root torque will play a major key role. Application of the same intrusive forces in labial and lingual systems in upper central incisor with different inclinations showed different responses.
The magnitudes of torque Loss during intrusive loads in incisors with normal, under and over-torque were higher in Labial system than Lingual orthodontic appliances.

\section{References}

1. Liang W, Rong Q, Lin J, Xu B. Torque control of the maxillary incisors in lingual and labial orthodontics: A 3 dimensional finite ele- 
ment analysis. Am J Orthod Dentofacial Orthop. 2009;135:316 22.

2. Scuzzo G, Takemoto K. Invisible Orthodontics: Current Concepts and Solutions in Lingual Orthodontics. 1st ed. Berlin: Quintessenz Verlag; 2003. using 3D FEM. Am J Orthod Dentofacial Orthop. 2003;123:441 50 .

3. Sung SJ, Baik HS, Moon YS, Yu HS, Cho YS. A comparative evaluation of different compensating curves in the lingual and labial techniques using 3D FEM. Am J Orthod Dentofacial Orthop. 2003;123:441 50.

4. Luca Lombardo, Giuseppe Scuzzo, Angela Arreghini . 3D FEM comparison of lingual and labial orthodontics in en masse retraction. Progress in Orthodontics. 2014, 15:38

5. Demling A, Dittmer MP, Schwestka-Polly R. Comparative analysis of slot dimension in lingual bracket systems. Head Face Med. 2009;5:27.

6. Liang W, Rong Q, Lin J, Xu B. Torque control of the maxillary incisors in lingual and labial orthodontics: a 3- dimensional finite element analysis. Am J Orthod Dentofacial Orthop. 2009;135:316-22.

7. Mahler DB, Peyton FA. Photoelasticity as a research technique for analyzing stresses in dental structures. J Dent Res. 1955;34:831-38.

8. Andersen KL, Pedersen EH, Melsen B. Material parameters and stress profiles within the periodontal ligament. Am J Orthod Dentofacial Orthoped. 1991;99:427-44.

9. Rudolph DJ, Willes MG, Sameshima GT. A finite element model of apical force distribution from orthodontic tooth movement. Angle Orthod. 2001;71:127-31.

10. Zienkiewicz OC. The Finite Element Method in Science. London: McGraw Hill; 1977.

11. Profitt William R, Fields Henry W, Jr. Contemporary Orthodontics (4th ed).

12. Robin N Mathew, Aneesh Katya, Ashutosh Shetty, Krishna Nayak. Effect of increasing the vertical intrusive force to obtain torque control in lingual orthodontics: A three dimensional finite element method study. Indian J Dent Res. 2016;27:163-7.

13. Scuzzo G, Takemoto K. Invisible Orthodontics: Current Concepts and Solutions in Lingual Orthodontics. 1st ed. 2003

14. Geron S, Romano R, Brosh T Vertical forces in labial and lingual orthodontics applied on maxillary incisors--a theoretical approach. Angle Orthod. 2004;74:195-201.

15. Liang W, Rong Q, Lin J, Xu B Torque control of the maxillary incisors in lingual and labial orthodontics: a 3-dimensional finite element analysis. Am J Orthod Dentofacial Orthop. 2009;35:316-322

16. Jost-Brinkmann PG, Tanne K, Sakuda M, Miethke RR A FEM study for the biomechanical comparison of labial and palatal force application on the upper incisors. Finite element method. Fortschr Kieferorthop. 1993 ;54:76-82.

17. Shum LMY, Wong RWK, Hägg U. Lingual Orthodontics-A Review. Hong Kong Dental Journal. 2004;1:13-20.

\section{Conflicts of Interest}

The authors state that they have no conflicts of interest. 